\title{
Lactoferrin protects against prion protein-induced cell death in neuronal cells by preventing mitochondrial dysfunction
}

\author{
YANG-GYU PARK ${ }^{1}$, JAE-KYO JEONG ${ }^{1}$, JU-HEE LEE ${ }^{1}$, YOU-JIN LEE ${ }^{1}$, JAE-WON SEOL ${ }^{1}$, SHANG-JIN KIM ${ }^{1}$, \\ TAI-YOUNG HUR ${ }^{2}$, YOUNG-HUN JUNG ${ }^{2}$, SEOG-JIN KANG ${ }^{2}$ and SANG-YOUEL PARK ${ }^{1}$ \\ ${ }^{1}$ Korea Zoonoses Research Institute, Bio-Safety Research Institute, College of Veterinary Medicine, \\ Chonbuk National University, Jeonju, Jeonbuk 561-756; ${ }^{2}$ National Institute of Animal Science, \\ Rural Development Administration, Cheonan, Chungnam 330-801, Republic of Korea
}

Received August 3, 2012; Accepted September 18, 2012

DOI: $10.3892 /$ ijmm.2012.1198

\begin{abstract}
Prion disorder-related neurodegenerative diseases are characterized by the accumulation of prion protein ( $\mathrm{PrP})$ scrapie isoform (PrPsc) within the central nervous system. PrPsc induces neuronal cell death by increasing intracellular generation of reactive oxygen species (ROS). Lactoferrin (LF) is an $80 \mathrm{kDa}$ protein, which has antioxidant abilities due to the scavenging of ROS. The effects of LF treatment on PrP (106-126)-mediated neurotoxicity and ROS generation were the focus of this study. LF treatment protected against PrP (106-126)-induced neuronal cell death and decreased ROS generation. The reduced ROS generation prevented PrP (106-126)-induced mitochondrial dysfunction. Moreover, PrP (106-126)-induced protein activation including c-Jun $\mathrm{N}$-terminal kinase and caspase-3 were blocked by LF treatment. These results demonstrated that LF protects neuronal cells against PrP (106-126)-mediated neurotoxicity through the scavenging of ROS and provide evidence that LF treatment prevents neuronal cell death caused by PrP (106-126).
\end{abstract}

\section{Introduction}

Prion diseases or transmissible spongiform encephalopathies (TSEs) are neurodegenerative disorders that are characterized by loss of motor control, dementia, central nervous system (CNS) spongiosis, and microglial activation $(1,2)$.

TSEs are caused by an infectious agent, prion, whose major component is a pathological form of the prion protein termed the scrapie isoform (PrPSc) (3). PrPsc acts as a template for the conversion of normal form of the prion protein (the cellular isoform, PrPc) to PrPsc (4). In many cases this is also accom-

Correspondence to: Professor Sang-Youel Park, Korea Zoonoses Research Institute, Bio-Safety Research Institute, College of Veterinary Medicine, Chonbuk National University, Jeonju, Jeonbuk 561-756, Republic of Korea

E-mail: sypark@chonbuk.ac.kr

Key words: lactoferrin, $\operatorname{PrP}(106-126)$, prion disease, reactive oxygen species scavenger panied by the accumulation of the PrPSc that leads to neuronal apoptosis, extensive neuronal loss, and mitochondrial disruption (5). Many pathogenic characteristics of PrPSc have been confirmed in a peptide corresponding to residues 106-126 of $\operatorname{PrP}[\operatorname{PrP}(106-126)]$ (6). Moreover, $\operatorname{PrP}$ (106-126) was reported to induce apoptotic cell death via dysregulation of mitochondrial homeostasis in neuronal cells (7). Thus, PrP (106-126) has been used as a model to study prion-induced neuronal cell death and has been postulated to induce mitochondrial dysfunction (8).

Mitochondria are essential organelles found in various cell types that play a principal role in cell survival and apoptotic cell death (9). Mitochondrial oxidative damage contributes to a range of degenerative diseases (10). Mitochondrial dysfunction caused by unnatural regulation of mitochondrial dynamic proteins may lead to neuropathological changes in prion disorders (11). In addition, PrP (106-126)-induced neuronal cell damage that occurs in neurodegenerative disorders causes mitochondrial disruption (12). Furthermore, oxidative stress is key in mitochondrial-mediated apoptotic cell death (13).

Oxidative stress is a baneful condition caused by reactive oxygen species (ROS) and/or a decrease in antioxidant levels (14). In neurodegenerative disorders, oxidative stressinduced neurodegeneration is mediated by ROS production (15). In addition, mitochondrial dysfunction is associated with ROS (16). PrP (106-126)-induced neuronal cell damage occurs in neurodegenerative disorders via regulation of cellular oxidation pathways (17).

Lactoferrin (LF) is an $80 \mathrm{kDa}$ protein found in colostrum, milk, and mucosal secretions such as blood, saliva, and tears (18). It is a multifunctional protein of the transferrin family, which is involved in the regulation of immune responses, regulation of neutrophil apoptosis, antioxidation, iron binding ability, and antimicrobial activity (19). The antioxidation capability of LF is due to the scavenging of ROS (20). For example, LF inhibits the subsequent production of ROS by neutrophils (21). However, the molecular mechanism of LF-mediated neuronal survival is only beginning to be understood.

We hypothesized that LF can prevent PrP (106-126)induced oxidative stress and neuronal cell death by regulating ROS generation. To test this hypothesis, we investigated the antioxidant effect of LF in PrP (106-126)-induced neuronal 
cell death. In particular, we tested whether LF protects from neuronal cell death by PrP (106-126) and assessed the therapeutic value of LF in the treatment of neurodegenerative disorders.

\section{Materials and methods}

Cell culture. The SH-SY5Y human neuroblastoma cell line was obtained from the American Type Culture Collection (ATCC, Rockville, MD, USA). Cells were cultured in Minimum Essential Medium (MEM; Invitrogen-Gibco, Grand Island, NY, USA) that contained $10 \%$ fetal bovine serum (FBS; Invitrogen-Gibco) and penicillin-streptomycin (both $100 \mathrm{U} / \mathrm{ml}$ ) in a humidified incubator maintained at $37^{\circ} \mathrm{C}$ and $5 \% \mathrm{CO}_{2}$.

Reagents. LF from bovine colostrums was purchased from Sigma-Aldrich (St. Louis, MO, USA). The antioxidant agents glutathione (GSH) and $\mathrm{N}$-acetylcysteine (NAC) were purchased from Sigma-Aldrich.

$\operatorname{PrP}$ (106-126) treatment. Synthetic PrP (106-126) (sequence, Lys-Thr-Asn-Met-Lys-His-Met-Ala-Gly-Ala-Ala-Ala-Ala-GlyAla-Val-Val-Gly-Gly-Leu-Gly) was synthesized by Peptron (Seoul, Korea). The peptide was dissolved in sterile dimethylsulfoxide (DMSO) at a concentration of $10 \mathrm{mM}$ and stored at $-80^{\circ} \mathrm{C}$.

Western blot analysis. SH-SY5Y was lysed in a buffer containing $25 \mathrm{mM}$ HEPES; pH 7.4, $100 \mathrm{mM} \mathrm{NaCl}, 1 \mathrm{mM}$ EDTA, $5 \mathrm{mM} \mathrm{MgCl}_{2}, 0.1 \mathrm{mM}$ dithiothreitol (DTT), and protease inhibitor mixture. Proteins were electrophoretically resolved by $10-15 \%$ sodium dodecyl sulfate-polyacrylamide gel electrophoresis (SDS-PAGE), and immunoblotting was performed as previously described. Equal amounts of lysate protein were similarly electrophoretically resolved and electrophoretically transferred to a nitrocellulose membrane. Immunoreactivity was detected through sequential incubation with horseradish peroxidase-conjugated secondary antibody and enhanced chemiluminescence reagents. The antibodies used for immunoblotting were phospho-c-Jun, N-terminal kinase (p-JNK; Santa Cruz Biotechnology, Inc., Santa Cruz, CA, USA), cleaved caspase-3 (Cell Signaling Technology, Danvers, MA, USA), and $\beta$-actin (Santa Cruz Biotechnology, Inc.).

Cellular fractionation. SH-SY5Y cells were resuspended in mitochondrial buffer $(210 \mathrm{mM}$ sucrose, $70 \mathrm{mM}$ mannitol, $1 \mathrm{mM}$ EDTA, $10 \mathrm{mM}$ HEPES), broken by a 26-gauge needle, and centrifuged at $700 \mathrm{x}$ g for $10 \mathrm{~min}$. The postnuclear supernatant was centrifuged at 10,000 $\mathrm{x}$ g for $30 \mathrm{~min}$. The pellet was used as the mitochondrial fraction and the supernatant was used as the cytosolic fraction. Total proteins were obtained and subjected to western blotting.

Annexin $V$ assay. Apoptosis was assessed by a commercial Annexin V assay (Santa Cruz Biotechnology, Inc.) according to the manufacturer's protocol. Annexin V content was determined by measuring fluorescence at an excitation wavelength of $488 \mathrm{~nm}$ and emission wavelengths of 525 and 530 using a Guava easyCyte HT System (Millipore, Billerica, MA, USA).
Immunofluorescence. SH-SY5Y cells cultured on glass coverslips were treated with PrP (106-126). Cells were washed with phosphate-buffered saline (PBS) and fixed with cold acetone for $90 \mathrm{sec}$. Cells were washed with PBS, blocked with 5\% FBS in Tris buffer saline containing Tween-20, and incubated with anti-caspase-3 $(2 \mu \mathrm{g} / \mathrm{ml})$ and anti-p-JNK $(2 \mu \mathrm{g} / \mathrm{ml})$ monoclonal antibodies for $48 \mathrm{~h}$ at $20^{\circ} \mathrm{C}$. Unbound antibody was removed by an additional PBS wash, and cells were incubated with labeled anti-rabbit Alexa Fluor 546 (for anti-caspase-3) IgG antibody $(4 \mu \mathrm{g} / \mathrm{ml})$ and Alexa Fluor 488 (for anti-p-JNK) IgG antibody $(4 \mu \mathrm{g} / \mathrm{ml})$ for $2 \mathrm{~h}$ at $20^{\circ} \mathrm{C}$. Finally, cells were mounted with DakoCytomation fluorescent medium and visualized via fluorescence microscopy.

Terminal deoxynucleotidyl transferase dUTP nick end labeling (TUNEL) assay. TUNEL analysis was performed to measure the degree of cellular apoptosis using an in situ ApoBrdU DNA fragmentation assay kit (BioVision, San Francisco, CA, USA) following the manufacturer's instructions.

DCFH-DA assay. SH-SY5Y cells were incubated in minimum essential medium (Hyclone Laboratories, Logan, UT, USA) containing $10 \mu \mathrm{M}$ 2',7'-dichlorodihydrofluorescein diacetate (H2-DCFDA) at $37^{\circ} \mathrm{C}$ for $30 \mathrm{~min}$. Cells were washed with PBS and lysed in the aforementioned lysis buffer. Cells were transferred to a clear 96-well plate and fluorescent emission from the bottom of the plate was measured at $515 \mathrm{~nm}$ with an excitation wavelength of $488 \mathrm{~nm}$ using a SpectraMax M2 instrument (Molecular Devices, Sunnyvale, CA, USA). SH-SY5Y cells were cultured on coverslips positioned in a 24-well plate. Cells were incubated in MEM (Hyclone Laboratories) containing $10 \mu \mathrm{M} \mathrm{H} 2-\mathrm{DCFDA})$ at $37^{\circ} \mathrm{C}$ for $30 \mathrm{~min}$. Cells were washed with PBS.

Mitochondrial transmembrane potential (MTP) assay. The change in MTP was evaluated by the cationic fluorescent indicator JC-1 (Molecular Probes, Eugene, OR, USA), which aggregates in intact mitochondria (red fluorescence) indicating high or normal MTP and low MTP when it remains in monomeric form in the cytoplasm (green fluorescence). SH-SY5Y cells were incubated in MEM containing $10 \mu \mathrm{M} \mathrm{JC}-1$ at $37^{\circ} \mathrm{C}$ for $30 \mathrm{~min}$, washed with PBS, and then transferred to a clear 96-well plate. JC-1 aggregate fluorescent emission was measured at $583 \mathrm{~nm}$ with an excitation wavelength of $526 \mathrm{~nm}$, and JC-1 monomer fluorescence intensity was measured with an excitation and emission wavelength of 525 and $530 \mathrm{~nm}$, respectively, using a Guava easyCyte HT System (Millipore). SH-SY5Y cells were cultured on coverslips in a 24-well plate, incubated in MEM containing $10 \mu \mathrm{m} \mathrm{JC}-1$ at $37^{\circ} \mathrm{C}$ for $30 \mathrm{~min}$, and then washed with PBS. Finally, cells were mounted with DakoCytomation fluorescent medium and visualized via fluorescence microscopy.

Statistical analysis. All data are expressed as the means \pm standard deviation (SD), and the data were compared using the Student's t-test and the ANOVA Duncan test with the SAS statistical package (SAS, Cary, NC, USA). The results were considered to indicate statistically significant differences at ${ }^{*} \mathrm{P}<0.05$ or ${ }^{* *} \mathrm{P}<0.01$. 


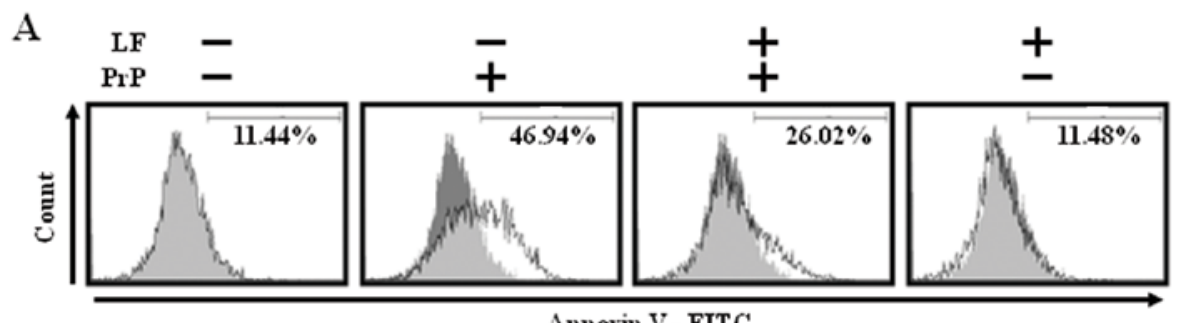

Annexin V - FITC

B

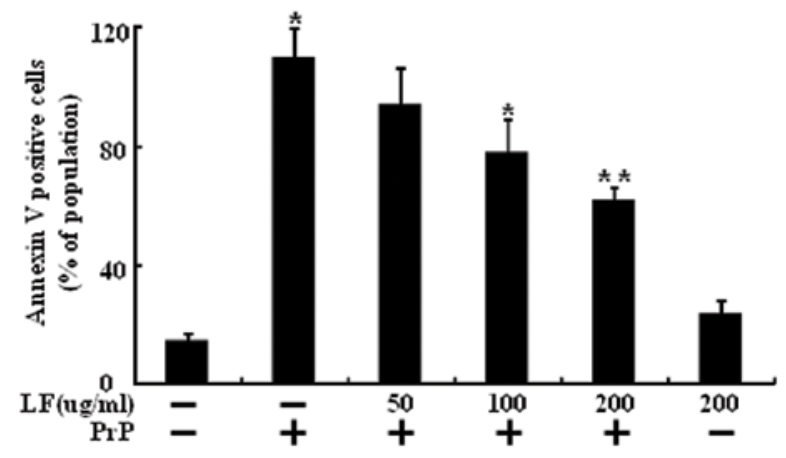

$\mathrm{C}$

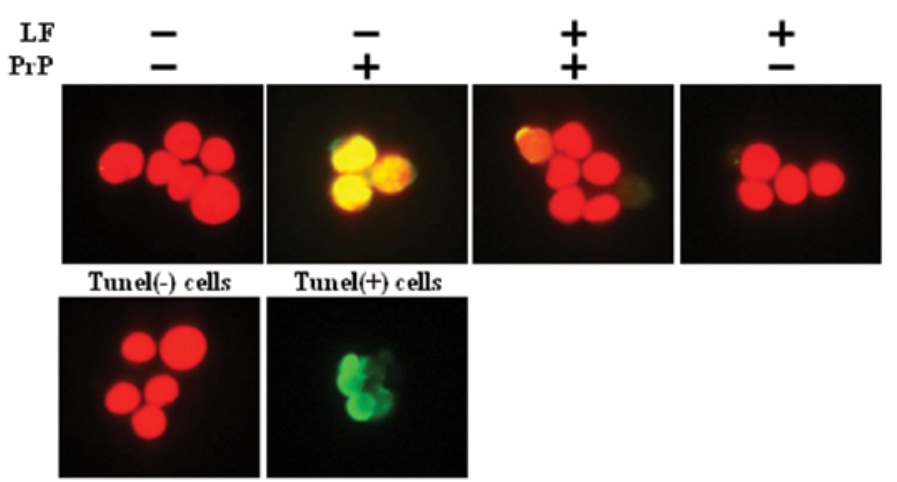

Figure 1. (A) LF protects against PrP (106-126)-induced neuronal cell damage. SH-SY5Y neuronal cells were pretreated with LF (12 h) and then exposed to $100 \mu \mathrm{M} \operatorname{PrP}(106-126)$ for $12 \mathrm{~h}$. Cell viability was measured by an Annexin V assay using flow cytometry. (B) Bar graph indicates the averages of Annexin V-positive cells. " $\mathrm{P}<0.05$ vs. control; ${ }^{* *} \mathrm{P}<0.01$ vs. $\operatorname{PrP}(106-126)$. (C) Representative immunofluorescence images of TUNEL-positive (white) SH-SY5Y cells at $12 \mathrm{~h}$ after exposure to $\operatorname{PrP}(106-126)(100 \mu \mathrm{M})$ in the absence or presence of $\operatorname{LF}(12 \mathrm{~h})$. The cells were counterstained with propidium iodide (dark gray) to show all cell nuclei. Magnification $\mathrm{x} 400$; scale bar, $100 \mu \mathrm{M}$.

\section{Results}

$\operatorname{PrP}$ (106-126)-induced neuronal cell death is decreased by $L F$ treatment in SH-SY5Y neuroblastoma cells. In a previous study, it was shown that LF inhibits prion accumulation (22). Thus, we presently examined whether LF protects against $\operatorname{PrP}$ (106-126)-mediated neurotoxicity. To study the influence of LF on PrP (106-126)-induced neuronal cell death, SH-SY5Y cells were pretreated with various concentrations of $\mathrm{LF}(12 \mathrm{~h})$ and then exposed to $100 \mu \mathrm{M} \operatorname{PrP}(106-126)$ for $8 \mathrm{~h}$ (Fig. 1B). The preventative effect of LF was evaluated using the Annexin V assay of cell viability. As shown in Fig. 1A, LF treatment prevented PrP (106-126)-induced neuronal cell death. SH-SY5Y cells were responsive to PrP (106-126) treatment (46.94\% increase in Annexin V-positive cells) and $\operatorname{PrP}$ (106-126)-induced neuronal cell death was decreased by LF pretreatment (Fig. 1A). TUNEL assay revealed the protective effect of LF on PrP (106-126)-induced apoptosis of SH-SY5Y cells (Fig. 1C). These results suggest that LF prevents PrP (106-126)-induced neuronal cell death.

LF treatment suppresses $\operatorname{Pr} P$ (106-126)-mediated protein activation. We examined the effects of LF treatment on the JNK and caspase-3 activation. Western blot analyses revealed that activation of JNK and caspase- 3 increased expression in the $100 \mu \mathrm{M} \operatorname{PrP}$ (106-126)-treated group compared to the LF (200 $\mu \mathrm{g} / \mathrm{ml})-$ pretreated group and the control group (Fig. 2A). PrP (106-126) treatment induced the activation of JNK and caspase-3 in SH-SY5Y cells. However, LF treatment inhibited the activation of JNK and caspase-3 (Fig. 2A and B). Consistent with these results, immunofluorescence monitoring also showed that LF treatment completely inhibited $\operatorname{PrP}$ (106-126)-mediated protein activation (Fig. 2C). These results suggest that LF treatment suppresses PrP (106-126)-induced protein activation. 
A

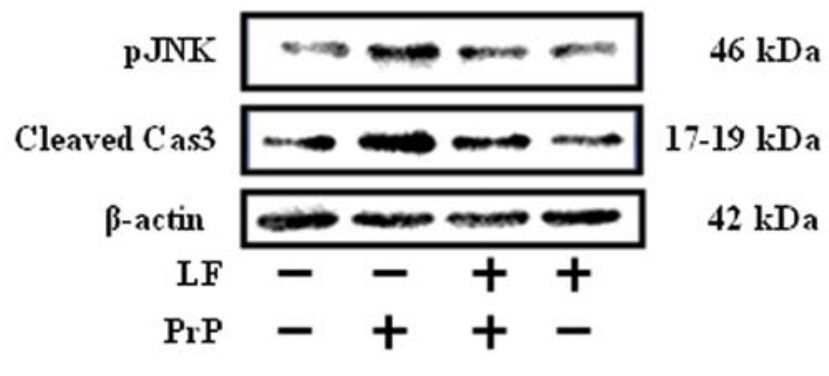

B
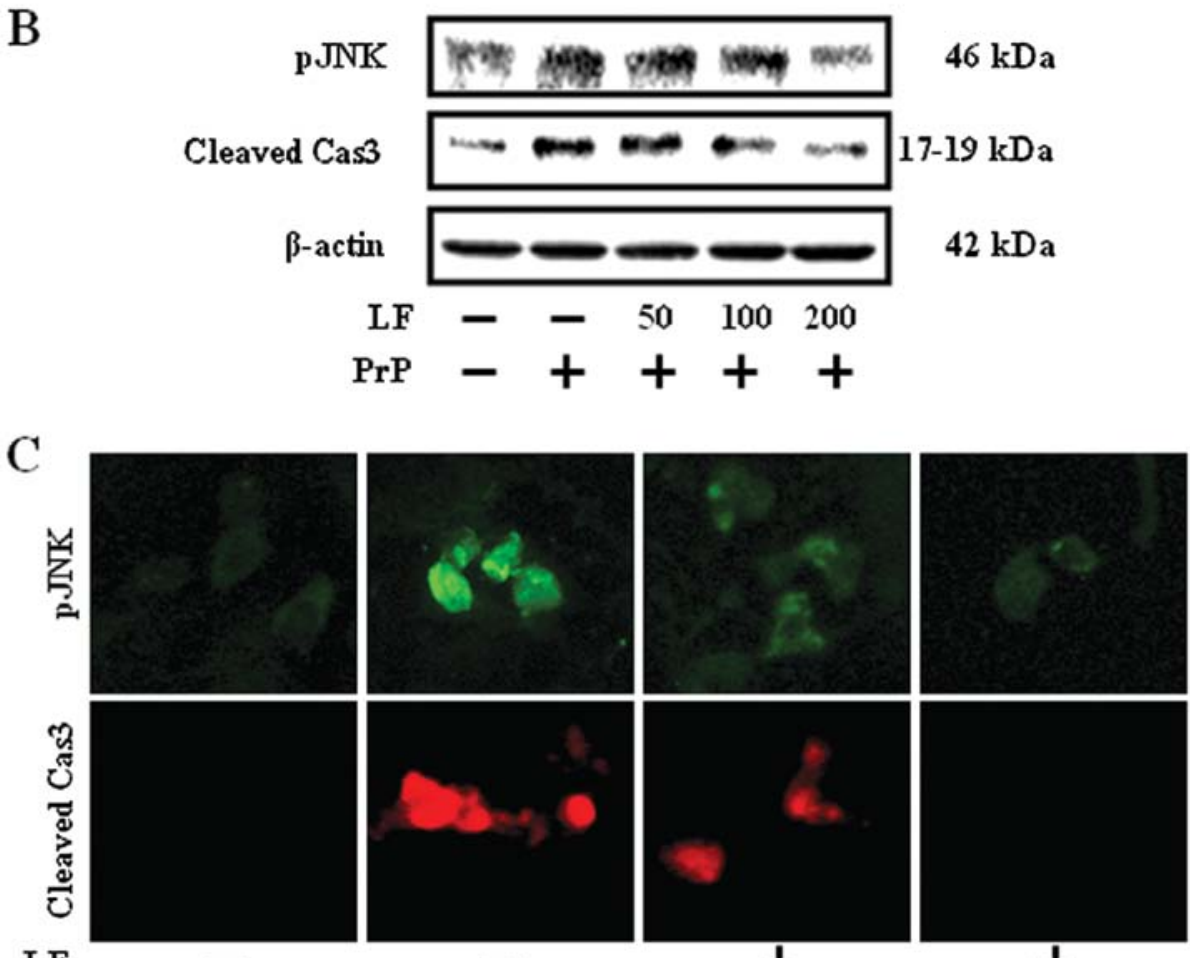

LF
PrP
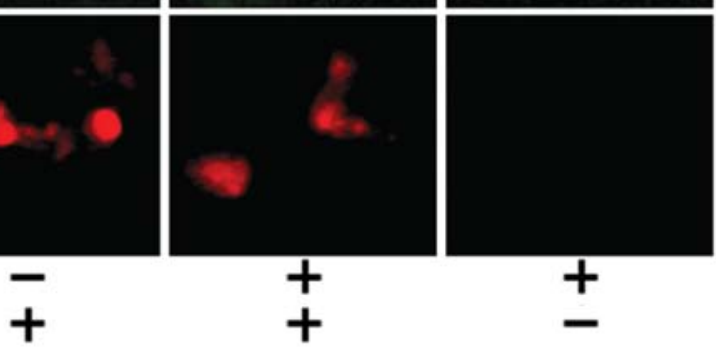

Figure 2. PrP (106-126)-induced JNK, Cas3 activation is attenuated by LF treatment. SH-SY5Y neuronal cells were pretreated with (A) LF (12 h) or (B) LF $(12 \mathrm{~h})$ in a dose-dependent manner, and then exposed to $100 \mu \mathrm{M} \operatorname{PrP}(106-126)$ for $12 \mathrm{~h}$. (C) The treated cells were assessed for phospho-JNK, cleaved Cas 3 production by western blot analysis. Results were normalized with $\beta$-actin. The treated cells were also assessed for phospho-JNK, cleaved Cas 3 production by immunofluorescence.

LF treatment decreases $\operatorname{PrP}$ (106-126)-induced oxidative stress via ROS scavenging. In a previous study, it was shown that LF is a scavenger of ROS (20), and that this protects against ROS-mediated cell death. PrP (106-126)-induced neuronal cell death is mediated by ROS generation (23). Thus, we next assessed whether the protective effect of LF on PrP (106-126)induced neuronal cell death was related to ROS generation. SH-SY5Y cells were preincubated $12 \mathrm{~h}$ with $200 \mu \mathrm{g} / \mathrm{ml} \mathrm{LF}$ and then exposed to $100 \mu \mathrm{M} \operatorname{PrP}$ (106-126) for $12 \mathrm{~h}$. LF treatment reduced PrP (106-126)-induced ROS generation (Fig. 1A). How LF treatment might induce PrP (106-126) resistance was studied by assessing the antioxidative properties and generation of ROS after treatment. Intracellular ROS production was spectrophotometrically measured by the DCFH-DA assay (Fig. 3A). After exposure to $100 \mu \mathrm{M} \operatorname{PrP}$ (106-126), DCF fluorescence intensity in SH-SY5Y cells increased significantly to $175 \%$ of the control value, whereas $\mathrm{LF}(200 \mu \mathrm{g} / \mathrm{ml})$ or antioxidants ( $800 \mu \mathrm{M}$ GSH or $4 \mathrm{mM}$ NAC) led to a decrease in DCF fluorescence intensity (Fig. 3B). These results suggest that
LF protects PrP (106-126)-induced neuronal cell death via the prevention of PrP (106-126)-induced ROS generation (Fig. 3C).

$\operatorname{PrP}$ (106-126)-induced mitochondrial dysfunction is suppressed by LF treatment. $\operatorname{PrP}(106-126)$-induced apoptosis is mediated by mitochondrial disruption (12). Mitochondrial dysfunction occurs after apoptotic signals, including loss of MTP and release of apoptotic factors into the cytosol (24). We examined the effects of LF or antioxidants on PrP (106-126)-induced mitochondrial dysfunction. MTP was measured by flow cytometry. PrP (106-126)-treated cells showed increased JC-1 monomers, while LF pretreatment reduced PrP (106-126)-induced JC-1 monomers (Fig. 4A). Furthermore, pretreatment of antioxidants also reduced PrP (106-126)-induced JC-1 monomers. These results were confirmed by fluorescence microscopy images of JC-1 stained cells (Fig. 4B). Consistent with these results, LF-treatment cells prevented PrP (106-126)-induced cytochrome $c$ release and Bax translocation (Fig. 4C). 

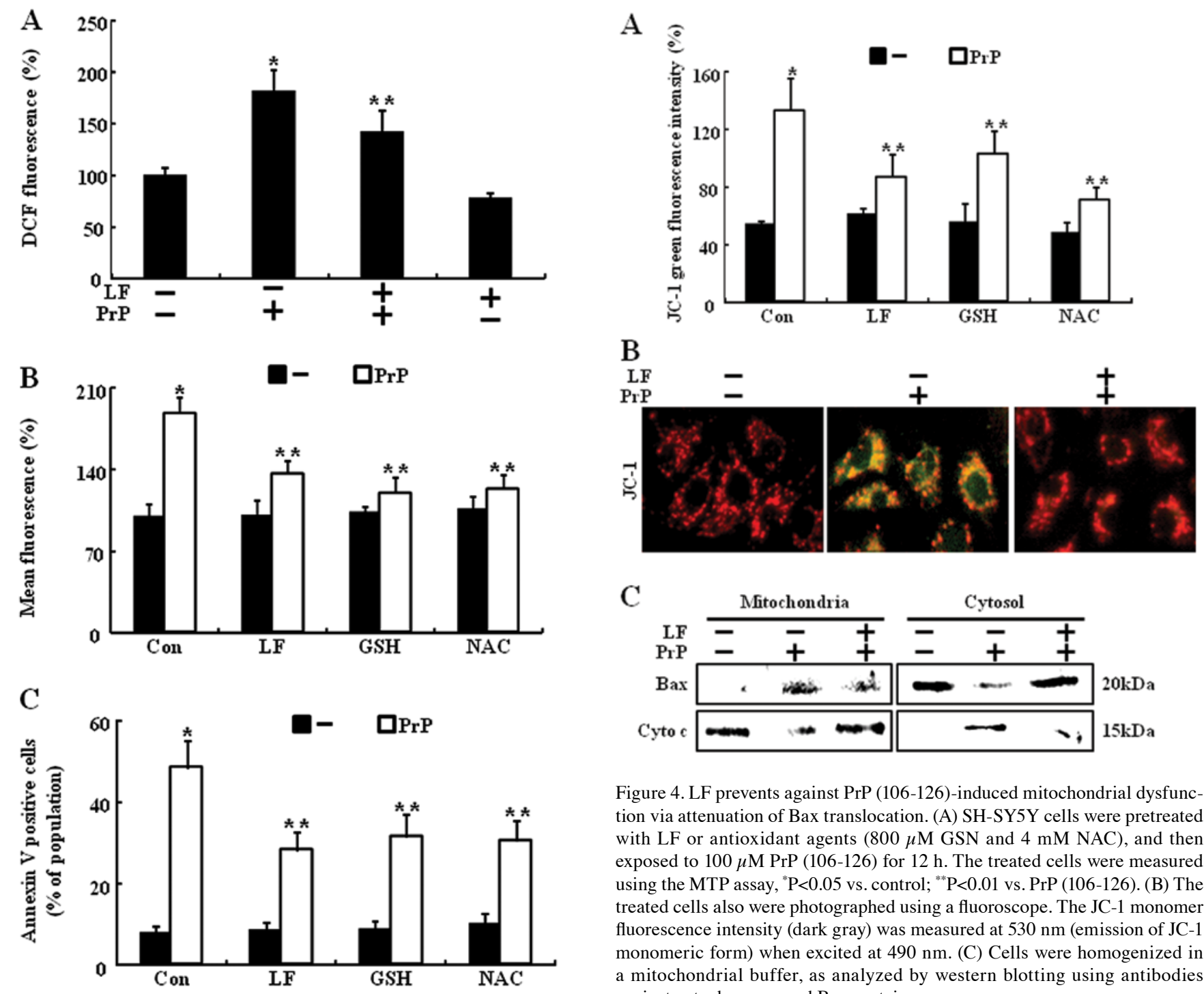

Figure 4. LF prevents against PrP (106-126)-induced mitochondrial dysfunction via attenuation of Bax translocation. (A) SH-SY5Y cells were pretreated with LF or antioxidant agents ( $800 \mu \mathrm{M} \mathrm{GSN}$ and $4 \mathrm{mM} \mathrm{NAC})$, and then exposed to $100 \mu \mathrm{M} \operatorname{PrP}(106-126)$ for $12 \mathrm{~h}$. The treated cells were measured using the MTP assay, ${ }^{*} \mathrm{P}<0.05$ vs. control; ${ }^{* *} \mathrm{P}<0.01$ vs. $\operatorname{PrP}(106-126)$. (B) The treated cells also were photographed using a fluoroscope. The JC-1 monomer fluorescence intensity (dark gray) was measured at $530 \mathrm{~nm}$ (emission of JC-1 monomeric form) when excited at $490 \mathrm{~nm}$. (C) Cells were homogenized in a mitochondrial buffer, as analyzed by western blotting using antibodies against cytochrome $c$ and Bax protein.

Figure 3. PrP (106-126)-induced ROS generation is suppressed by LF treatment. SH-SY5Y neuronal cells were pretreated with (A) LF or (B) antioxidant agents ( $800 \mu \mathrm{M} \mathrm{GSN}$ and $4 \mathrm{mM} \mathrm{NAC}$ ), and then exposed to $100 \mu \mathrm{M}$ $\operatorname{PrP}(106-126)$ for $12 \mathrm{~h}$. The treated cells were used for measuring ROS release with the (A) DCFH-DA assay spectrophotometrically or (B) by flow cytometry ${ }^{*} \mathrm{P}<0.05$ vs. control; ${ }^{* *} \mathrm{P}<0.01$ vs. $\operatorname{PrP}(106-126)$. (C) The treated cells or antioxidant agents ( $800 \mu \mathrm{M}$ GSN and $4 \mathrm{mM} \mathrm{NAC})$ were then exposed to $100 \mu \mathrm{M} \operatorname{PrP}(106-126)$ for $12 \mathrm{~h}$. Cell viability was measured by the Annexin $\mathrm{V}$ assay via flow cytometry.

\section{Discussion}

Prion diseases are fatal neurodegenerative disorders (25). The main component of prion disease is the abnormal isoform of prion protein (PrPsc) (26). PrP (106-126) maintains the neurotoxic characteristics of the entire pathological PrPSc and is commonly used as a suitable model to study the mechanism of prion disorders (5). However, this peptide mechanism is not fully understood. In previous studies, it has been shown that PrP (106-126) induces neurotoxicity via mitochondrial disruption and ROS generation. LF is an $80 \mathrm{kDa}$ protein. It is a multifunctional protein of the transferrin family and its functions include antimicrobial activity, antibacterial activity, cell proliferation, and antioxidant ability (27). LF protects from programmed cell death via antioxidant activity that is due

to the scavenging of ROS (20). Moreover, LF inhibits PrPsc accumulation in scrapie-infected cells (22). However, the affirmative effect of LF on PrP (106-126)-induced neuronal cell death is not completely understood. In this study, LF treatment protected against $\operatorname{PrP}$ (106-126)-induced neuronal cell death (Fig. 1). In addition, PrPc-deficient mice were more sensitive to oxidative stress (28). Oxidative stress plays an important role in neurodegenerative disorders (13). Thus, we considered whether LF treatment could mediate ROS scavenger ability. Our results demonstrate that LF protects against PrP (106-126)-induced ROS generation in SH-SY5Y cells (Fig. 3A and B). These results suggest that $\operatorname{PrP}$ (106-126) mediates apoptotic cell death and ROS generation, and that these consequences are decreased by LF treatment. ROS can activate JNK protein. Indeed, $\operatorname{PrP}(106-126)$ induces neuronal cell damage by activating JNK and caspase-3 proteins (Fig. 2). JNK activation has been documented in neurodegenerative diseases (29). By contrast, LF treatment inhibits PrP (106-126)-mediated protein activation including JNK and caspase-3 (Fig. 2). These results indicate that LF treatment inhibits PrP (106-126)-mediated JNK and caspase-3 activation, and support the view that LF-mediated ROS scavenging downregulates PrP (106-126)-mediated 
protein activation. NAC protects cells against mitochondrial dysfunction (30). Furthermore, PrP (106-126)-induced apoptotic cell death occurs through mitochondrial disruption in neuronal cells (12). Our findings additionally show that LF or antioxidants (GSH and NAC) prevent neuronal cell death due to $\operatorname{PrP}$ (106-126)-mediated mitochondrial dysfunction (Fig. 4). Collectively, these results indicate that LF treatment protects from $\operatorname{PrP}$ (106-126)-induced neuronal cell death by ROS scavenging associated antioxidant activity. Moreover, LF possesses antioxidant activity and prevents $\operatorname{PrP}$ (106-126)-mediated mitochondrial disruption. In addition, these findings also suggest that LF may have clinical benefits when used for neurodegenerative chemotherapy such as in patients with prion disorders.

\section{Acknowledgements}

This study was supported by the Cooperative Research Program for Agriculture Science and Technology Development (PJ907116) in Rural Development Administration and by the National Research Foundation of the Korea Grant funded by the Korean Government (2010-E00019).

\section{References}

1. Beringue V, Couvreur P and Dormont D: Involvement of macrophages in the pathogenesis of transmissible spongiform encephalopathies. Dev Immunol 9: 19-27, 2002.

2. Ermolayev V, Cathomen T, Merk J, et al: Impaired axonal transport in motor neurons correlates with clinical prion disease. PLoS Pathog 5: e1000558, 2009.

3. Ogayar A and Sanchez-Perez M: Prions: an evolutionary perspective. Int Microbiol 1: 183-190, 1998.

4. Bate $\mathrm{C}$ and Williams A: Monoacylated cellular prion protein modifies cell membranes, inhibits cell signaling, and reduces prion formation. J Biol Chem 286: 8752-8758, 2011.

5. Hur K, Kim JI, Choi SI, Choi EK, Carp RI and Kim YS: The pathogenic mechanisms of prion diseases. Mech Ageing Dev 123: 1637-1647, 2002.

6. Florio T, Paludi D, Villa V, et al: Contribution of two conserved glycine residues to fibrillogenesis of the 106-126 prion protein fragment. Evidence that a soluble variant of the 106-126 peptide is neurotoxic. J Neurochem 85: 62-72, 2003.

7. Anantharam V, Kanthasamy A, Choi CJ, et al: Opposing roles of prion protein in oxidative stress- and ER stress-induced apoptotic signaling. Free Radic Biol Med 45: 1530-1541, 2008.

8. Jeong JK, Moon MH, Lee YJ, Seol JW and Park SY: Autophagy induced by the class III histone deacetylase Sirtl prevents prion peptide neurotoxicity. Neurobiol Aging: May 8, 2012 (Epub ahead of print).

9. Nicholls DG and Budd SL: Mitochondria and neuronal survival. Physiol Rev 80: 315-360, 2000.

10. Murphy MP and Smith RA: Targeting antioxidants to mitochondria by conjugation to lipophilic cations. Annu Rev Pharmacol Toxicol 47: 629-656, 2007.

11. Choi SI, Ju WK, Choi EK, et al: Mitochondrial dysfunction induced by oxidative stress in the brains of hamsters infected with the $263 \mathrm{~K}$ scrapie agent. Acta Neuropathol 96: 279-286, 1998.
12. O'Donovan CN, Tobin D and Cotter TG: Prion protein fragment PrP-(106-126) induces apoptosis via mitochondrial disruption in human neuronal SH-SY5Y cells. J Biol Chem 276: 43516-43523, 2001.

13. Kitazawa M, Wagner JR, Kirby ML, Anantharam V and Kanthasamy AG: Oxidative stress and mitochondrial-mediated apoptosis in dopaminergic cells exposed to methylcyclopentadienyl manganese tricarbonyl. J Pharmacol Exp Ther 302: 26-35, 2002.

14. Blokhina O, Virolainen E and Fagerstedt KV: Antioxidants, oxidative damage and oxygen deprivation stress: a review. Ann Bot 91: 179-194, 2003.

15. Park KW and Jin BK: Thrombin-induced oxidative stress contributes to the death of hippocampal neurons: role of neuronal NADPH oxidase. J Neurosci Res 86: 1053-1063, 2008.

16. Wang J, Yu Y, Hashimoto F, Sakata Y, Fujii M and Hou DX: Baicalein induces apoptosis through ROS-mediated mitochondrial dysfunction pathway in HL-60 cells. Int J Mol Med 14: 627-632, 2004.

17. Pietri M, Caprini A, Mouillet-Richard S, et al: Overstimulation of PrPC signaling pathways by prion peptide 106-126 causes oxidative injury of bioaminergic neuronal cells. J Biol Chem 281: 28470-28479, 2006.

18. Tuccari G and Barresi G: Lactoferrin in human tumours: immunohistochemical investigations during more than 25 years. Biometals 24: 775-784, 2011.

19. Brock JH: The physiology of lactoferrin. Biochem Cell Biol 80: $1-6,2002$

20. Burrow H, Kanwar RK and Kanwar JR: Antioxidant enzyme activities of iron-saturated bovine lactoferrin (Fe-bLf) in human gut epithelial cells under oxidative stress. Med Chem 7: 224-230, 2011 .

21. Baveye S, Elass E, Mazurier J and Legrand D: Lactoferrin inhibits the binding of lipopolysaccharides to L-selectin and subsequent production of reactive oxygen species by neutrophils. FEBS Lett 469: 5-8, 2000.

22. Iwamaru Y, Shimizu Y, Imamura M, et al: Lactoferrin induces cell surface retention of prion protein and inhibits prion accumulation. J Neurochem 107: 636-646, 2008.

23. Jeong JK, Seol JW, Moon MH, et al: Cellular cholesterol enrichment prevents prion peptide-induced neuron cell damages. Biochem Biophys Res Commun 401: 516-520, 2010.

24. Kroemer G, Galluzzi L and Brenner C: Mitochondrial membrane permeabilization in cell death. Physiol Rev 87: 99-163, 2007.

25. Harris DA: Cellular biology of prion diseases. Clin Microbiol Rev 12: 429-444, 1999.

26. Sakudo A and Ikuta K: Prion protein functions and dysfunction in prion diseases. Curr Med Chem 16: 380-389, 2009.

27. Hedlin P, Taschuk R, Potter A, Griebel P and Napper S: Detection and control of prion diseases in food animals. ISRN Veterinary Sci 2012: 24, 2012.

28. Brown DR and Besinger A: Prion protein expression and superoxide dismutase activity. Biochem J 334: 423-429, 1998.

29. Tsirigotis M, Baldwin RM, Tang MY, Lorimer IAJ and Gray DA: Activation of p38MAPK contributes to expanded polyglutamineinduced cytotoxicity. PLoS One 3: e2130, 2008.

30. Mai S, Klinkenberg M, Auburger G, Bereiter-Hahn J and Jendrach M: Decreased expression of Drp1 and Fis1 mediates mitochondrial elongation in senescent cells and enhances resistance to oxidative stress through PINK1. J Cell Sci 123: 917-926, 2010. 